\title{
Pharmacist Intervention in Treatment of Patients With Genotype 1 Chronic Hepatitis C
}

\author{
Eduardo L. Mariño, PhD; Luis Álvarez-Rubio, PhD; Silvia Miró, MD; Pilar Modamio, PhD; \\ Fernando Baños, MD; Cecilia F. Lastra, PhD; and Aintzane Alberdi-Leniz, PharmD
}

C hronic hepatitis C infection affects nearly 300 million people worldwide. It is one of the main causes of chronic liver disease and the most common indication for liver transplantation..$^{1-5}$ There are 6 major strains or genotypes of hepatitis $\mathrm{C}$ virus (HCV). These genotypes have different geographic distributions, with the type 1 genotype (HCV-1) most common in the United States (accounting for about $75 \%$ of cases) ${ }^{6}$ and in Spain where it is responsible for $60 \%-70 \%$ of all cases of chronic hepatitis $C^{7}$ The most effective initial therapy for patients with this disorder is the combination of interferon alfa-2b with ribavirin. ${ }^{8,9}$ More recently, there has been a modification of interferon alfa-2b with the addition of a polyethylene glycol molecule to interferon (peginterferon) to produce a biologically active molecule with a longer half-life than the natural molecule, and more favorable pharmacokinetics; these characteristics allow for convenient once-weekly dose administration. ${ }^{6,10,11}$

In 2001, an important randomized clinical trial was published with peginterferon alfa-2b plus ribavirin in combination therapy administered over 24-48 weeks as a function of the infective virus genotype. The results of the trial indicated sustained viral response (SVR) of $42 \%$ in patients infected with HCV-1 and 54\% in the sample overall. ${ }^{12}$ Experience gained from clinical trials indicates that HCV genotypes 2 and 3 are highly susceptible to current combination therapy regimens, whereas genotype 1 has a lower response rate to interferon-based therapies. The recommended length of treatment for HCV-1 is 48 weeks. ${ }^{13}$ Because genotype 1 is both the most prevalent type and is associated with a lower viral response rate and greater potential liver-related morbidity and mortality, ${ }^{7}$ it is important to know the outcome of treatment of HCV-1 in studies conducted in routine clinical practice. $^{14}$

Although HCV genotype is the main determinant of response of therapy, additional factors, such as adherence to recommended dose and duration of treatment, significantly influence the probability of achieving SVR. A retrospective analysis documented that patients who receive more than $80 \%$ of their interferon doses and more than $80 \%$ of their ribavirin doses for more than $80 \%$ of the duration of therapy (the 80/80/80 rule) had significantly higher SVR, compared with patients with worse adherence. This effect was more apparent in patients infected with HCV-1 than in those infected with

Note: This article is the subject of a commentary that appears on pages 151-153 of this issue. other HCV genotypes. ${ }^{15}$

Studies have suggested that coordinated care between pharmacists and physicians improves patient care outcomes. ${ }^{16,17}$ With the advent of pharmaceutical medication therapy management, pharmacists have focused their services on the care of the patient and have become integral members of care teams. The role of pharmacists in optimizing treatment response and managing adverse effects in HCV infection is recognized. . $^{18,19}$ However, pharmacy interventions on the therapeutic outcomes in patients with chronic HCV have not been sufficiently evaluated. ${ }^{20-22}$ A recent pilot study showed that safe and effective management of $\mathrm{HCV}$ infection can be achieved under the care of a clinical pharmacist. After finding that treatment outcomes in the pilot program and in earlier studies managed with traditional care were similar, authors concluded that further studies to investigate the pharmacist's role in the management of patients with HCV infection are necessary. ${ }^{21}$ Kolor described how interventions carried out by pharmacists at an HCV clinic provided critical support for patients with $\mathrm{HCV} .^{22}$

\section{Objective and Methods}

To describe the results of pharmacist interventions in optimizing response in treatment-naïve patients with chronic HCV-1 infection, a prospective, open-label study was conducted from December 2002 through June 2006 at a 373-bed secondary care hospital in Catalonia, Spain. Male and female patients aged 18-70 years with compensated chronic HCV-1 infection (HCV ribonucleic acid [RNA] detectable at more than 6 months), not previously treated with interferon, ribavirin, and/or amantadine, were eligible for enrollment. All patients had an initial visit with the hepatologist for evaluation of severity of the disease and clinical history record. No liver biopsy was obtained from the patients included in the study because histologic findings were not considered a determinant in deciding on therapy commencement. None of the patients were diagnosed with alcohol or drug abuse. The HCV genotypes were established in all of the patients treated in the hospital. Leukocyte and platelet counts had to be at least 3,000 and 80,000 per microliter, respectively, for entry into the study and hemoglobin values needed to be at least 12 grams per deciliter $(\mathrm{dL})$ for females and 13 grams per $\mathrm{dL}$ for males. The values of these parameters were considered important since treatment has the potential to cause leukopenia or anemia. Patients that were coinfected with human immunodeficiency virus were excluded from the study. 
A convenience sample of 50 consecutive patients was enrolled in the study. Patients who met inclusion criteria were interviewed and verbal consent was obtained; written consent was not required according to the Independent Ethics Committee of the hospital because the study protocol did not compromise the standard practice of care

All patients were treated with peginterferon alfa-2b, with 1.5 micrograms per kilogram $(\mathrm{kg})$ administered subcutaneously once a week. Ribavirin was administered orally as a function of patient body weight: for patients less than $65 \mathrm{~kg}$, a dose of 800 milligrams (mg) per day ( 2 capsules in the morning and 2 at night); between 65 and $85 \mathrm{~kg}$, a dose of 1,000 mg per day (2 capsules in the morning and 3 at night); and more than $85 \mathrm{~kg}$, a dose of 1,200 mg per day ( 3 capsules in the morning and 3 at night). The doses of ribavirin or peginterferon alfa-2b were adjusted if anemia or neutropenia were present. The duration of treatment was 48 weeks, although therapy was to be suspended at 12 weeks of treatment for patients who did not achieve early viral response (EVR), defined as a reduction in viral load (HCV RNA International Units per milliliter [IU per $\mathrm{mL}$ ]) of at least 2 times $\log _{10} \cdot 23$

After the initial visit to the hepatologist, patients were directed to a consultation with the pharmacy department. In addition to the information about disease and treatment that is routinely provided by hepatologists, pharmacists provided drug therapy management, education, and support. The goal of the pharmacist-managed process was to turn patients into active subjects of the therapeutic plan by establishing a collaborative agreement with them. The pharmacist provided information about the therapeutic plan, administration method, the need for adherence to the treatment schedule, the management of any adverse drug effects should they occur, what to do if a dose is forgotten, how to store the medication, and dietetic recommendations. All information was presented orally and reinforced graphically and with written text.

At each successive visit, the pharmacist identified, recorded, and counseled the patient about the management of drug-related problems. Pharmacists emphasized that the benefits of therapy ultimately may outweigh the inconvenience of adverse events and educated patients about how to cope with these situations. For example, patients experiencing influenza-like symptoms were encouraged to get plenty of sleep, keep well hydrated, and use acetaminophen or a nonsteroidal anti-inflammatory drug therapy. Hematological events were managed with dosage reduction, gastrointestinal events with specific dietary recommendations, dermatological events with topical steroid creams or shooting baths, psychiatric and neurological events with antidepressant therapy, and endocrine events by encouraging patients to eat well-balanced meals to maintain weight. If adverse drug effects were detected that warranted medical treatment, the pharmacist contacted the hepatologist for an emergency visit with the patient. Because adherence is particularly important early in treatment, pharmacists motivated patients when EVR was measured at 12 weeks by reminding them that EVR is a good predictor of SVR.

Adherence was monitored at each scheduled clinical visit by inspecting the pill boxes that were provided to the patient. Monitoring by the attending hepatologist was at weeks 4,10 , $16,22,28,36,44$, and 48 . Monitoring by the pharmacist was at weeks $4,8,14,20,24,32,40$, and 48 . Pharmacists and hepatologists interposed their consultations with the patients so that an in-depth follow-up to monitor safety, assess therapeutic effectiveness, and enhance quality of life would be provided. In addition, pharmacists provided support to the patients after hours, on holidays, and on weekends. If required, the patients were provided follow-up visits before the standard 4 weeks, and the maximum period between visits did not exceed 6 weeks. These face-to-face encounters helped the pharmacist to monitor patients closely, not only to identify and manage adverse events, but also to assess whether strategies were effectively promoting adherence. The adherence rate, measured using the 80/80/80 rule, was calculated.

\section{Results}

All patients were of European descent with a mean age of 43 years (age range: $28-62$ years) and 68\% were male. Pretreatment viral load was high (greater than 850,000 IU per mL) for 22 patients (44.0\%), and 96\% had elevated alanine aminotransferase (ALT) at the start of treatment. None of the patients had clinical or biochemical evidence of hepatic decompensation. The rate of EVR was $68.0 \%(n=34)$. Treatment was suspended in 30.0\% $(n=15)$ of the patients in accordance with the treatment protocol because there was no evidence of EVR. Of the patients who had EVR, 70.6\% $(n=24)$ maintained SVR. SVR was achieved in $57.1 \%$ of patients who had a low pretreatment viral load (16 of 28) and $36.4 \%$ of those with a high pretreatment viral load (8 of 22). The mean adherence rate was $85.7 \%$ in the sample overall and $95.5 \%$ in patients who achieved SVR.

One patient voluntarily withdrew from the study after 4 weeks of treatment. Treatment was suspended in 2 patients because of adverse drug effects. In the first case, the patient had anemia (World Health Organization grade 4) that did not respond to a decrease in dose. In the second case, the patient developed diabetes type 1 . The remaining patients $(n=32)$ completed the full course of the treatment.

Adverse effects were reported in $94 \%$ of the patients, with a mean of 5 episodes per patient; $68.0 \%(n=34)$ had at least 3 distinct adverse effects over the course of the treatment. Medical treatment of the adverse effects was required in $12 \%$ of the patients. Frequencies of adverse drug events are presented in Table 1. It was necessary to reduce the peginterferon dose in 5 patients who developed grade 3 neutropenia and both peginterferon and ribavirin dose in 2 patients who developed grade 3 neutropenia plus grade 3 or 4 anemia. Weight loss occurred in $38.0 \%$ ( $n=19$ ) of patients because of loss of appetite and $24.0 \%(n=12)$ of patients suffered a weight loss of more than $10 \%$. 


\section{Discussion}

Antiviral treatment of chronic hepatitis $\mathrm{C}$ infection has improved over the past decade, initially with the incorporation of the combined therapy interferon alfa- $2 \mathrm{~b}$ plus ribavirin and more recently with the introduction of peginterferon alfa- $2 \mathrm{~b}$ plus ribavirin. Because the therapy is associated with an unfavorable tolerability profile, the management of adverse events to stay the course to reduce viral load is very important. These aspects have resulted in the need for increased efforts to optimize rates of diagnosis, treatment, and evaluation of hepatitis $C$ patients. ${ }^{23,24}$ The overall rate of SVR obtained in our study, $48.0 \%$, was comparable to the rate of $41.7 \%$ measured in a 2001 study by Manns et al..$^{12}$ The dose of ribavirin in this study was lower than that used in routine clinical practice. When a new analysis was performed in the Manns et al. study with patients who had received ribavirin in doses greater than $10.6 \mathrm{mg}$ per $\mathrm{kg}$, the rate of SVR was $47.5 \% .^{12}$

The low rate of early discontinuation of treatment in our hospital (6.0\%) may have increased the percentage of patients achieving SVR. McHutchison et al. (2002) demonstrated that adherence to treatment improved the effectiveness of the interferon plus ribavirin combination. ${ }^{15}$ Weiss et al. (2008) found high rates of adherence (95.5\%) to combined treatment, as measured by survey self-report. ${ }^{25}$ However, the authors explained these high adherence rates as the result of the tendency of self-report to overestimate adherence and the possible screening out of patients at high risk for nonadherence. ${ }^{25,26}$ In our study, treatment adherence as measured by inspecting pill boxes was $85.7 \%$, even though $68.0 \%$ of patients experienced at least 3 adverse treatment effects. Thus, our results are promising, although preliminary because our study lacked a comparison group and enrolled only 50 patients.

\section{Conclusions}

Pharmacists are in a good position to improve the treatment of patients with HCV-1 as part of the multidisciplinary patient care team. The structure of the team of health care professionals involved in the follow-up of our study patients promoted collaboration between the physicians and pharmacists. Therefore, pharmacists were able to identify and respond to potential opportunities for improvements in medication use. Pharmacists assisted patients with adverse effects, drug compliance, disease state and medication information, and overall treatment goals; these efforts increased the probability of HCV treatment success. Although these results are promising, more study is needed to provide quantitative evidence of treatment outcomes.

\section{DISCLOSURES}

The authors report no financial or other conflicts of interest associated with the subject of this article.

Mariño, Álvarez-Rubio, and Modamio were responsible for concept and design with assistance by Baños, Lastra, and Miró. Álvarez-Rubio performed data collection with assistance from Baños, Miró, and Alberdi-Leniz. Writing of this manuscript was shared equally by Alberdi-Leniz, Baños, Lastra, and Miró. Mariño and Modamio performed the data interpretation and revision of the manuscript with assistance from all of the other authors.
TABLE 1$)$ Adverse Drug Effects $(n=50)$

\begin{tabular}{l|l|c}
\hline \multirow{4}{*}{$\begin{array}{l}\text { Psychiatric and } \\
\text { neurological }\end{array}$} & \multicolumn{1}{|c|}{$\begin{array}{c}\text { Adverse Drug Effect } \\
\text { an adverse drug effect }\end{array}$} & Study Patients (\%) \\
\hline \multirow{2}{*}{ Hematological } & Insomnia & 6 \\
\cline { 2 - 3 } & Depression & 33 \\
\cline { 2 - 3 } & Concentration loss & 29 \\
\hline \multirow{2}{*}{ Endocrine } & Neutropenia & 17 \\
\cline { 2 - 3 } & Anemia & 26 \\
\hline \multirow{2}{*}{$\begin{array}{l}\text { Dermatological } \\
\text { symptumza-like }\end{array}$} & Fatigue & 5 \\
\cline { 2 - 3 } & Anorexia & 51 \\
\cline { 2 - 3 } & Skin eruptions & 38 \\
\cline { 2 - 3 } & Fever & 24 \\
\cline { 2 - 3 } & Myalgia & 52 \\
\cline { 2 - 3 } & Arthralgia & 43 \\
\hline \multirow{2}{*}{ Gastrointestinal } & Diarrhea & 38 \\
\cline { 2 - 3 } & Nausea/vomiting & 16 \\
\hline
\end{tabular}

Adverse effects reported at any time during 48-week follow-up period.

\section{Authors}

Eduardo L. Mariño, PhD, is Full Professor at the Faculty of Pharmacy, University of Barcelona. Luis Álvarez-Rubio, PhD, is Associate Pharmacist, Hospital General L'Hospitalet, Barcelona. Silvia Miró, MD, is Associate Physician, Hospital General L'Hospitalet, Barcelona. Pilar Modamio, PhD, is Lecturer at the Faculty of Pharmacy, University of Barcelona. Fernando Baños, MD, is Associate Physician, Hospital General L'Hospitalet, Barcelona. Cecilia F. Lastra, PhD, is Full Professor at the Faculty of Pharmacy, University of Barcelona. Aintzane Alberdi-Leniz, PharmD, is Associate Pharmacist, Hospital Clinic, Barcelona.

CORRESPONDENCE: Eduardo L. Mariño, PhD, Clinical Pharmacy and Pharmacotherapy Unit, Department of Pharmacy and Pharmaceutical Technology, University of Barcelona, Faculty of Pharmacy. Av. Joan XXIII s/n, Barcelona, Spain 08028. Tel: +34.934024544; Fax: +34.934035714; Email: emarino@ub.edu

\section{REFERENCES}

1. Detre KM, Belle SH, Lombardero M. Liver transplantation for chronic viral hepatitis. Viral Hepatitis Rev. 1996;2:219-28.

2. Center for Disease Control and Prevention (CDC). Recommendations for prevention and control of hepatitis C virus (HCV) infection and HCV-related chronic disease. MMWR Recommen Rep. 1998;47(RR-19):1-39.

3. Alter MJ, Kruszon-Moran D, Nainan OV, et al. The prevalence of hepatitis C virus infection in the United States, 1988 through 1994. N Engl J Med. 1999;341(8):556-62.

4. National Institutes of Health. National Institutes of Health Consensus Development Conference Statement: Management of hepatitis C: 2002June 10-12, 2002. Hepatology. 2002;36(5 Suppl 1):S3-S20. 
5. McHutchison JG. Understanding hepatitis C. Am J Manag Care. 2004;10(2 Suppl):S21-S29.

6. McHutchison JG, Bacon BR. Chronic hepatitis C: an age wave of disease burden. Am J Manag Care. 2005;11(10 Suppl):S286-S295.

7. Bravo R, Soriano V, García-Samaniego J, et al. Hepatitis C virus genotypes in different risk populations in Spain. The Hepatitis-HIV Spanish Study Group. J Infect Dis. 1996;173(2):509-10.

8. McHutchison JG, Gordon SC, Schiff ER, et al. Interferon alfa-2b alone or in combination with ribavirin as initial treatment for chronic hepatitis C. N Engl J Med. 1998;339:1485-92.

9. Poynard T, Marcellin P, Lee SS, et al. Randomised trial of interferon alfa$2 \mathrm{~b}$ plus ribavirin for 48 weeks or for 24 weeks versus interferon alfa $2 \mathrm{~b}$ plus placebo for 48 weeks for treatment of chronic infection with hepatitis $C$ virus. Lancet. 1998;352(9138):1426-32.

10. Glue P, Fang JW, Rourizer-Panis R, et al. Pegylated interferon alfa-2b: pharmacokinetics, pharmacodynamics, safety, and preliminary efficacy data. Clin Pharmacol Ther. 2000;68(5):556-67.

11. Hughes CA, Shafran SD. Chronic hepatitis C virus management: 20002005 update. Ann Pharmacother. 2006;40(1):74-82

12. Manns MP, McHutchison JG, Gordon SC, et al. Pegylated interferon alfa-2b plus ribavirin compared with interferon alfa-2b plus ribavirin for initial treatment of chronic hepatitis C: a randomised trial. Lancet. 2001;358(9286):958-65.

13. Dienstag JL, McHutchison JG. American Gastroenterological Association technical review on the management of hepatitis C. Gastroenterology. 2006;130(1):231-64.

14. Bacon BR, McHutchison JG. Treatment issues with chronic hepatitis C: special populations and pharmacy strategies. Am J Manag Care. 2005;11(10 Suppl):S296-S306

15. McHutchison JG, Manns M, Patel K, et al. Adherence to combination therapy enhances sustained response in genotype-l-infected patients with chronic hepatitis C. Gastroenterology. 2002;123(4):1061-69.
16. Kaboli PJ, Hoth AB, McClimon BJ, Schnipper JL. Clinical pharmacists and inpatient medical care: a systematic review. Arch Intern Med. 2006;166(9):955-64.

17. Viktil KK, Blix HS. The impact of clinical pharmacists on drugrelated problems and clinical outcomes. Basic Clin Pharmacol Toxicol. 2008;102(3):275-80.

18. Rodis J. Chronic hepatitis $C$ virus infection: a review for pharmacists. J Am Pharm Assoc. 2007;47(4):508-20.

19. Smith JP. Treatment options for patients with hepatitis C: role of pharmacists in optimizing treatment response and managing adverse events. Pharmacotherapy. 2008;28(9):1151-61.

20. Shatin D, Schech SD, Patel K, McHutchison JG. Population-based hepatitis $C$ surveillance and treatment in a national managed care organization. Am J Manag Care. 2004;10(4):250-56.

21. Smith JP, Dong MH, Kaunitz JD. Evaluation of a pharmacist-managed hepatitis C care clinic. Am J Health-Syst Pharm. 2007;64(6):632-36.

22. Kolor B. Patient education and treatment strategies implemented at a pharmacist-managed hepatitis $C$ virus clinic. Pharmacotherapy. 2005;25(9):1230-41.

23. Bacon BR, McHutchison JG. Into the light: strategies for battling hepatitis C. Am J Manag Care. 2007;13(Suppl 12):S319-S326.

24. McHutchison JG, Bacon BR, Owens GS. Making it happen: managed care considerations in vanquishing hepatitis C. Am J Manag Care. 2007;13(Suppl 12):S327-S336.

25. Weiss JJ, Bhatti L, Dieterich DT, et al. Hepatitis C patients' self-reported adherence to treatment with pegylated interferon and ribavirin. Aliment Pharmacol Ther. 2008;28(3):289-93.

26. Smith SC, Wahed AS, Kelley SS, Conjeevaram HS, Robuck PR, Fried MW; Virahep-C Study Group. Assessing the validity of self-reported medication adherence in hepatitis C treatment. Ann Pharmacother. 2007;41(7):1116-23. 